\title{
EL CASO DE LA ESCUELA NORMAL SUPERIOR
}

\section{Roberto Pineda Giraldo*,}

Parecería rigorismo extremo identificar cuatro etapas en la vida de la institución, cuya existencia cubrió el corto lapso de tres lustros: fundación, época dorada, transición y decadencia y desmonte, tal como las han establecido para la extinguida Escuela Normal Superior de Colombia, los profesores Martha Cecilia Herrera y Carlos Low en su documentado estudio sobre el origen, vida, pasión, muerte y legado de la ya legendaria institución, que hoy presenta en pulcrísima y docta edición — supongo que con justo orgullola Universidad Pedagógica Nacional, una de sus herederas académicas. Los solos nombres con que se definen y precisan, sugieren para cada una períodos de formación y consolidación de mediana o larga duración; en la realidad, sin embargo, la más duradera, la época dorada, que abarca la rectoría del doctor José Francisco Socarrás, sólo alcanzó a escasos ocho años.

Indudablemente, la tosudez de los hechos, reconstruidos con base en documentos y entrevistas a personas comprometidas en su momento con la Escuela, mostró a los investigadores la realidad de esas transiciones, que se podrían calificar de fugaces, pero que son, en síntesis, efecto, en un momento de inestabilidad política, de la intolerancia ideológica y religiosa de una minoría, en su afán por retrotraer al escenario nacional filosofías, prácticas y fanatismos ya superados en otros mundos desde el siglo XVIII y contra los cuales una avanzada de intelectuales y políticos había emprendido, un decenio antes, una campaña que fue exitosa, pero de corta duración entonces. El coletazo final de la reacción mostró tener más vigor momentáneo que el que, aparentemente, habían logrado consolidar las reformas liberales. Los desarrollos posteriores mostrarían que la verdad era a la inversa.

Quince años, que son un mero instante en el devenir de una nación, eran en la época, apenas la cuarta parte de la vida de no muchos colombianos, o un tiempo estrecho para alcanzar un título educativo de pregrado, pero en ningún caso, un lapso suficiente para que un organismo creado a propósito para llevar a cabo las transformaciones educacionales implícitas en el ideario de un partido en el poder, comprometido ideológica y políticamente con ellas, logrará su cometido; menos aún, en cuanto en tanto éstas implicaban subvertir, pacíficamente desde luego, no sólo la filosofía y la praxis tradicionales de la educación, sino contribuir, por medio de ella, al cambio de la estructura social prevaleciente. La formación de un licenciado en sus aulas tornaba cuatro años y la cobertura de profesores especializados para la enseñanza secundaria, para impartir y dirigir la cual se preparaban, demandaba varios miles de ellos; en toda la existencia de la ENS los egresados fuimos seiscientos cincuenta. Superar el déficit de arrastre y satisfacer las demandas del crecimiento ponderado de la población escolar del ciclo secundario, tendría que haber sido obra de continuidad

\footnotetext{
*, Roberto Pineda Giraldo. Nació en Abejorral (Antioquía). Licenciado en Ciencias Sociales y Económicas en la Escuela Normal Superior de Colombia (1944); obtuvo su grado de Etnólogo en 1943 en el Instituto Etnológico Nacional; hizo estudios de Especialización en Antropología y Geografía Cultural en la Universidad de California (Berkeley) y de Planeación del Desarrollo Económico en la CEPAL. Se doctoró en la Universidad Pedagógica Nacional. Actualmente adelanta una investigación sobre "Misegenación y Cultura en la Colombia Colonial 17501810", en unión de su esposa la Antropóloga Virginia Gutiérrez de Pineda. 
prolongada de la Escuela y de creación de nuevos organismos con estructura similar a la suya, y el respaldo académico de sus egresados, tarea de programación a largo plazo que no tuvo concreción.

No obstante ello, la proyección de lo que podría llamarse la filosofía Normalista (así con mayúscula), trascendió casi de inmediato y en intensidad, mucho más que en extensión, a la enseñanza universitaria y a la investigación, particular y notoriamente en las disciplinas sociales y humanas, fundamentadas en la especialización de Ciencias Sociales y, por breves años, en el Instituto Etnológico Nacional, las primeras y en el Departamento de Filología e Idiomas, muy vinculado al Instituto Caro y Cuervo, las segundas.

A mi entender, ese impacto es la demostración probatoria de las premisas implícitas en el proyecto Escuela Normal Superior y en la mente y el ánimo de algunos de sus gestores y directivos, entre los cuales vuelve a resaltar la figura de José Francisco Socarrás. Como premisas necesarias yo nombraría de una parte, la convicción de políticos e intelectuales en la necesidad y conveniencia de transformar radicalmente la educación secundaria, profesionalizando a los maestros; la claridad de algunos de ellos sobre la manera efectiva de realizar los cambios con celeridad y sobre los efectos colaterales que a mediano y largo plazo provocarían en la sociedad nacional; la voluntad política de los hombres de estado para crear la institución apropiada y apoyarla con decisión frente a los ataques de adversarios inteligentes y todavía poderosos; la mística que permeó e identificó a académicos y estudiantes y los individualizó con una impronta indeleble; y de otra, un ambiente general alentador y receptivo, entre cuyos componentes figuran la disponibilidad, por azares de la II Guerra Mundial y de la Guerra Civil española ("por muerte de unos viven otros", enseña el adagio popular) de profesores extranjeros con carreras académicas brillantes en sus países, algunas reconocidas internacionalmente; de figuras de la generación nueva nacional, ansiosas de participar en el proyecto; de sectores amplios de población que veían en él el principio de reivindicaciones largamente demandadas y nunca atendidas y de una juventud, sin distingos de sexos, impregnada de un espíritu nacionalista sin chauvinismos, que aspiraba a penetrar en la génesis de su sociedad y en el análisis del potencial recursívo, para visualizar el futuro y proyectarse a sí misma en él.

No creo aventurado afirmar que el éxito sin precedentes de la Escuela fue, en grado importante, responsable de la acervía de la reacción. Los procesos de cambio cultural (y el concepto de cultura incluye desde luego la política, la educación y las formas económicas) logran su momento y sé enraizan más firmemente en las generaciones jóvenes que en las de edades superiores, porque mientras éstas arraigan la ética de sus comportamientos en el ethos tradicional por largos años asimilado, aquéllas no están todavía suficientemente atadas a las tradiciones y, por lo mismo, absorben con facilidad propuestas y ejemplos de nuevas formas de relación, de pensamientos revolucionarios y de comportamientos más acordes con las nuevas circunstancias que la inevitable evolución de las sociedades impone; es en ellas donde están las mentalidades abiertas y los espíritus ansiosos de lo nuevo, porque no se sienten, como las generaciones más viejas, ni incómodas ni inseguras situadas en el escenario al cual convergen las vicisitudes, inconsistencias e incertidumbres y, por qué no, también los traumas que arrastra tras de sí cada cambio de impacto renovador revolucionario. Y esto lo entendían muy bien quienes querían mantener un status quo que preservaba un orden socioeconómico asaz semejante a los patrones de la era colonial; comprendían que la juventud normalista, imbuída de las ideas nuevas, provocaría un efecto multiplicador exponencial en generaciones de adolescentes muy cercanas a la suya, suficien- 
te para borrar de ellas, en corto tiempo, el bagaje acumulado de su corto proceso de socialización informal y formal.

La Escuela Normal Superior feneció como organismo, en la arena partidista y fanática de la época, pero su espíritu permaneció, y traigo a relación el símil utilizado por Kalidasa en su Sakhuntala, para figurar el sentimiento del príncipe, que va a partir para la guerra, y se despide de su amada con este símil —palabra más, palabra menos, pues estoy citando de memoria-: "Me voy, mi cuerpo sigue adelante, pero mi espíritu se queda atrás, como la seda de un estandarte que se lleva contra el viento". El espíritu de la Escuela Normal Superior se quedó en sus egresados, no para estancarse, ni para rumiar añoranzas, ni para acudir periódicamente a un imaginario muro de lamentaciones, sino para seguir el avance con contribuciones pedagógicas, educacionales y científicas, cuyos alcances ya están siendo evaluados por los estudiosos del proyecto educativo más intenso de la "República Liberal", entre ellos los profesores Herrera y Low, cuyo libro se presenta hoy y las generaciones recientes de historiadores, antropólogos, etc., las cuales, de una u otra forma, son conscientes de que su ancestro científico guarda una relación de ascendencia con esa institución.

Los ex alumnos de la Escuela Normal Superior vimos claro desde los ya lejanos tiempos de escolares, que la mayor parte de las cátedras impartidas en cada especialización eran de alta calidad y renovadoras de teorías, conceptos y métodos; y también, que había carencias y estatismo en otras, debido a la no disponibilidad de personas calificadas para ellas o a concesiones políticas y académicas, tal vez convenientes, pero nunca innecesarias. Un balance desprevenido adjudicará el más alto porcentaje a las primeras; y, como disculpa a nuestras propias incapacidades, permítannos argumentar, que una parte - los expertos dirán en qué proporción- de las debilidades de nuestra formación intelectual y, consecuentemente, las inconsistencias y fallas de nuestros aportes como profesionales, son atribuibles a las segundas.

El libro que nos congrega hoy, aporta materiales para un juicio sobre el producto final de la Escuela Normal Superior; su documentación, además de suministrar datos fehacientes sobre algunos de los temas, sugiere fuentes de consulta y vías adecuadas para quienes en el futuro pudieren interesarse en estudios de extensión y/o profundización del efectuado por los doctores Herrera y Low. La ordenación temporal y temática que ellos con acierto le dieron a su investigación, y los análisis y comentarios que derivaron a partir de ella, tras dejar un amplio camino abierto a nuevos inquiridores, le entrega al lector una visión acertada, exenta de sesgos, del proceso y le sugiere algunas de las consecuencias positivas derivadas de él, con presencia sobresaliente, de la del valor de la autonomía universitaria, de su inmunización contra componendas políticas de gobiernos y partidos; y la de la rigurosidad académica.

Para nosotros, ex alumnos de esa alma mater, la lectura de El caso de la Escuela Normal Superior nos deleita con recuerdos de momentos académicos vividos en nuestra juventud, cuyo influjo aún nos estimula y toca fibras que se balancean entre la mente y el sentimiento, que bordean los límites de los dos hemisferios cerebrales. A los autores les expreso mi agradecimiento por uno de esos momentos que compartí, el 13 de abril de este año, con mi esposa, Virginia Gutiérrez y nuestro colega el profesor Darío Mesa, cuando leimos y comentamos el acta del seminario de geografía de Colombia, bajo la dirección del profesor Vila, fechada el mismo día del año de 1943 y firmada por Darío Mesa, como responsable del registro de la sesión correspondiente, que transcribe el libro. Cincuenta y un 
años después, reflexionamos, una vez más, sobre la trascendencia de la metodología de los seminarios introducida en la Normal Superior, que distensionaba la rigidez cortante de la cátedra magistral, enseñaba el valor metodológico del uso apropiado de la documentación y del trabajo en equipo, creaba un vínculo de colegaje entre profesores y estudiantes y el sentido crítico entre pares, principios necesarios de toda investigación científica. A ellos seguimos apegados, con la misma intensidad con que vinculamos nuestra vida a los ideales que nos enseñó la ESCUELA. Y como los seminarios, tantas otras innovaciones que hicieron de ella lo que fue, que es lo que los autores han rescatado para la historia de la educación en Colombia. 